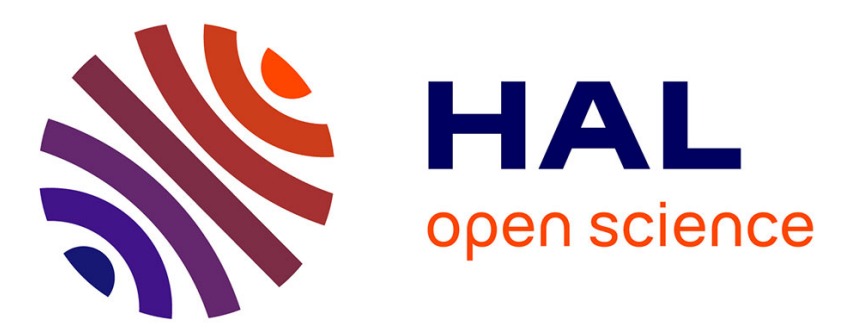

\title{
SEISMIC BEARING CAPACITY OF SHALLOW STRIP FOOTINGS IN SEISMIC CONDITIONS.
}

\author{
Abdul-Hamid Soubra
}

\section{To cite this version:}

Abdul-Hamid Soubra. SEISMIC BEARING CAPACITY OF SHALLOW STRIP FOOTINGS IN SEISMIC CONDITIONS.. Proceedings of the ICE - Geotechnical Engineering, 1997, 125 (4), pp.230 - 241. 10.1680/igeng.1997.29659 . hal-01007274

\section{HAL Id: hal-01007274 https://hal.science/hal-01007274}

Submitted on 30 Jan 2019

HAL is a multi-disciplinary open access archive for the deposit and dissemination of scientific research documents, whether they are published or not. The documents may come from teaching and research institutions in France or abroad, or from public or private research centers.
L'archive ouverte pluridisciplinaire HAL, est destinée au dépôt et à la diffusion de documents scientifiques de niveau recherche, publiés ou non, émanant des établissements d'enseignement et de recherche français ou étrangers, des laboratoires publics ou privés. 


\title{
Seismic bearing capacity of shallow strip footings in seismic conditions
}

\author{
A.-H. Soubra
}

The seismic bearing capacity factors of shallow strip footings are calculated. The approach used is pseudo-static, where the seismic effects are considered by taking into account static inertia forces. The upperbound method of limit analysis is used. Two failure mechanisms, referred to as the M1 and M2 mechanisms, are considered for the calculation schemes. These mechanisms are non-symmetrical. M1 consists of a $\log$ sandwich composed of a triangular active wedge, a log-spiral radial shear zone and a triangular passive wedge. M2 consists of an arc sandwich composed of a triangular active wedge, a circular radial shear zone and a triangular passive wedge. The solutions obtained are rigorous upper-bound ones in the framework of the limit analysis theory for an associated flow rule Coulomb material. For the static case, the numerical results of the bearing capacity factors show that the M1 mechanism gives the exact wellknown solutions of both the $N_{\mathrm{cS}}$ and $N_{\mathrm{qS}}$ factors. This is not the case with the M2 mechanism. However, for the $N_{\gamma \mathrm{S}}$ factor, the lowest upper-bound solutions are obtained from the M1 mechanism for $\phi>30^{\circ}$ and from the M2 mechanism for $\phi<30^{\circ}$. For the seismic case, the lowest upper-bound solutions of the seismic bearing capacity factors obtained from both the M1 and M2 mechanisms are presented in the form of design charts for practical use in geotechnical engineering. These results are compared with other authors' results.

$\begin{array}{ll}\begin{array}{l}\text { Notation } \\ B_{0}\end{array} & \text { width of footing } \\ c & \text { cohesion } \\ \Delta D_{\mathrm{AC}}, \Delta D_{\mathrm{CD}}, \Delta D_{\mathrm{DE}} & \begin{array}{l}\text { incremental internal energy dissi- } \\ \text { pation along } \mathrm{AC}, \mathrm{CD} \text { and } \mathrm{DE},\end{array} \\ & \text { respectively } \\ \Delta D_{\mathrm{L}} & \begin{array}{l}\text { incremental internal energy dissi- } \\ \text { pation }\end{array} \\ \Delta D_{\mathrm{rad}} & \text { incremental internal energy dissi- } \\ & \text { pation along the radial lines of the } \\ & \text { log spiral or the circular shear } \\ & \text { zone } \mathrm{BCD} \\ & \begin{array}{l}\text { velocity along a velocity disconti- } \\ \text { nuity }\end{array} \\ \Delta W_{\mathrm{ABC}}, \Delta W_{\mathrm{BCD}}, & \text { incremental external work of re- } \\ \Delta W_{\mathrm{BDE}} & \text { gions } \mathrm{ABC}, \mathrm{BCD} \text { and BDE, re- } \\ & \text { spectively }\end{array}$

\begin{tabular}{|c|c|}
\hline$\Delta W_{\mathrm{P}}, \Delta W_{\mathrm{q}}$ & $\begin{array}{l}\text { incremental external work due to } \\
\text { the foundation load and surcharge }\end{array}$ \\
\hline$f_{1}, \ldots f_{11}$ & $\begin{array}{l}\text { non-dimensional intermediate } \\
\text { functions }\end{array}$ \\
\hline$g_{1}, \ldots g_{11}$ & $\begin{array}{l}\text { non-dimensional intermediate } \\
\text { functions }\end{array}$ \\
\hline$K_{\mathrm{h}}$ & horizontal seismic coefficient \\
\hline$N_{\gamma \mathrm{S}}, N_{\mathrm{cS}}, N_{\mathrm{qS}}$ & static bearing capacity factors \\
\hline$N_{\gamma \mathrm{E}}, N_{\mathrm{cE}}, N_{\mathrm{qE}}$ & seismic bearing capacity factors \\
\hline$P$ & ultimate foundation load \\
\hline$q$ & surcharge loadings \\
\hline$q_{\mathrm{c}}$ & ultimate bearing capacity \\
\hline$r, \theta$ & polar coordinates of the surface $C D$ \\
\hline$r_{0}$ & $\begin{array}{l}\text { initial ray of the log-spiral surface, } \\
\text { i.e. BC }\end{array}$ \\
\hline$\Sigma[\Delta D]$ & totalincremental energy dissipation \\
\hline$\Sigma[\Delta W]_{\mathrm{ext}}$ & total incremental external work \\
\hline$V$ & velocity \\
\hline$V_{1}$ & velocity of the triangle $A B C$ \\
\hline & velocity of the triangle $\mathrm{BDE}$ \\
\hline$W_{\mathrm{ABC}}, W_{\mathrm{BDE}}$ & $\begin{array}{l}\text { weights of regions } \mathrm{ABC} \text { and } \mathrm{BDE} \text {, } \\
\text { respectively }\end{array}$ \\
\hline $\mathrm{d} W$ & $\begin{array}{l}\text { elementary weight in the radial } \\
\text { shear zone BCD }\end{array}$ \\
\hline$\alpha, \beta$ & $\begin{array}{l}\text { angular parameters of the failure } \\
\text { mechanisms }\end{array}$ \\
\hline$\phi$ & angle of internal friction of the soil \\
\hline$\gamma$ & unit weight of the soil \\
\hline
\end{tabular}

\section{Introduction}

While the investigation of bearing capacity in non-seismic areas has been reported at length in the literature, ${ }^{1-7}$ the seismic bearing capacity of strip footings has not been studied in detail in the past. The traditional method for evaluating the effect of an earthquake load on the stability of a soil-foundation system is the so-called 'pseudo-static method'. This method continues to be used by consulting geotechnical engineers because it is required by the building codes; it is easy to apply and gives satisfactory results. The very few studies available in the literature describing the seismic effect on the bearing capacity of foundations concern the work of Meyerhof $^{8}$ and Shinohara et al. ${ }^{9}$ Both approaches are pseudo-static: horizontal and vertical accelerations are applied to the centre of gravity of the structure and the problem is reduced to a static case of bearing capacity with inclined eccentric loads. However, in these solutions, the inertia of the soil mass is not included. Recently, Sarma and Iossifelis ${ }^{10}$ have suggested a method for calculating the seismic bearing capacity of strip footings in seismic areas by considering the inertia forces on all parts of 
the soil-structure system (soil and foundation). Their method is based on an approach which they have been using for the analysis of slopes; it is a limit equilibrium method based on an a priori assumption concerning the inter-slice forces. It is well known that this category of methods gives approximate solutions of the failure load and that the solution cannot be said to be an upper- or a lower-bound one with respect to the exact solution. In this paper we present an upper-bound limit analysis method. This method allows us to get a rigorous upperbound solution with respect to the exact solution for an associated flow rule Coulomb material obeying Hill's maximal work principle. This method is detailed in the following section.

\section{Assumptions}

2. An earthquake has two possible effects on a soil-foundation system. One is to increase the driving forces. The other is to reduce the shearing resistance of the soil. The reduction in the shearing resistance of a soil occurs only when the magnitude of the earthquake exceeds a certain limit and the ground conditions are favourable for such a reduction. In this paper, only the reduction of the bearing capacity factors due to the increase in driving forces is investigated under seismic loading conditions. The shear strength of the soil is assumed to remain unaffected by the seismic loading. The assumptions made in the analysis can be summarized as follows.

(a) The soil is homogeneous and isotropic. It is assumed to be an associated flow rule Coulomb material obeying Hill's maximal work principle.

(b) The effect of pore water pressure is not included.

(c) A one-sided failure mechanism is assumed to occur.

(d) Only the reduction of the bearing capacity due to the increase in driving forces is investigated under seismic loading conditions. The shear strength of the soil is assumed to remain unaffected by the seismic loading.

(e) As was mentioned before, all inertias of the soil-structure system are considered.

(f) The earthquake acceleration for both the soil and the structure is assumed to be the same. Only the horizintal seismic coefficient $K_{\mathrm{h}}$ is considered, the vertical seismic coefficient being often disregarded.

(g) The earthquake load on the structure is represented by the base shear load acting at the foundation level and an eccentricity for the vertical foundation load. The moment due to the seismic load on the structure is not considered. Only the base shear load will be taken into account.

\section{The upper-bound theorem of limit analysis}

3. The upper-bound theorem of limit analysis states that, for a kinematically admissible velocity field, an upper-bound of the exact collapse load can be obtained by equating the power dissipated internally to the power expended by the external loads. A kinematically admissible velocity field is one that satisfies the flow rule, the velocity boundary conditions and compatibility. During plastic flow, power is assumed to be dissipated by general plastic yielding of the soil mass, as well as by sliding along velocity discontinuities where jumps in the normal and tangential velocities may occur. Note that the velocity field at collapse is often modelled by a mechanism of rigid blocks that move with constant velocities. Since no general plastic deformation of the soil mass is permitted to occur, the power is dissipated solely at the interfaces between adjacent blocks, which constitute velocity discontinuities. This kind of velocity field will be used here. Finally, it should be noted that in the case of the bearing capacity problem, the upper-bound theorem gives an unsafe estimate of the failure load.

\section{Failure mechanisms}

4. As was mentioned above, to obtain upperbound solutions for the bearing capacity problem, a kinematically admissible failure mechanism must be considered. According to the normality condition for an associated flow rule Coulomb material, for a kinematically admissible failure mechanism the velocity along a plastically deformed surface must make an angle $\phi$ with this velocity discontinuity. If the kinematically admissible mechanism is chosen, the work equation is obtained by equating the rate of external work done by the external forces to the rate of internal energy dissipation along the plastically deformed surfaces. Finally, the critical failure load is then obtained after extremization of the 'potential' failure load.

5. In a previous paper, Soubra and Reynolds ${ }^{11}$ have presented a rotational non-symmetrical failure mechanism for the seismic bearing capacity of strip footings on slopes. The results obtained overestimate the currently accepted results in the static and seismic cases. In this paper, the traditional translational mechanisms proposed by Terzaghi ${ }^{1}$ and Chen $^{6}$ will be used by applying the upper-bound method of limit analysis in order to obtain rigorous upperbound solutions. Two translational failure mechanisms, referred to as the M1 and M2 mechanisms, are considered for the calculation schemes.

\section{M1 mechanism}

6. This mechanism has been used by Dormieux and Pecker ${ }^{12}$ to calculate the seismic bearing capacity factor $N_{\gamma \mathrm{E}}$ of a cohesionless 
soil. As shown in Fig. 1 this mechanism is composed of a triangular active wedge $\mathrm{ABC}$, a log-spiral radial shear zone $\mathrm{BCD}$ and a triangular passive wedge BDE. It is a log-sandwich mechanism and will be referred to here as the M1 mechanism. The log-spiral slip surface CD is assumed to be a tangent to lines $\mathrm{AC}$ and $\mathrm{DE}$ at $\mathrm{C}$ and $\mathrm{D}$, respectively. This mechanism is defined by the two angular parameters $\alpha$ and $\beta$.

7. The triangular wedge $\mathrm{ABC}$ is assumed to be rigid. It moves with velocity $V_{1}$, which makes an angle $\phi$ with the discontinuity line AC in order to respect the normality condition for an associated flow rule Coulomb material. The foundation is assumed to move with the same velocity as the wedge $\mathrm{ABC}$ (i.e. $V_{1}$ ); hence there is no dissipation of energy along the soilstructure interface.

8. The radial log-spiral shearing zone $\mathrm{BCD}$ is bounded by a log-spiral curve $\mathrm{CD}$, where the equation for the curve in polar coordinates $(r, \theta)$ is $r=r_{0} \exp (\theta \tan \phi)$; the centre of this $\log$-spiral $\mathrm{CD}$ is at point $\mathrm{B}$ and the radius $r_{0}$ is the length of the line $\mathrm{BC}$. Note that in this mechanism we have assumed that the line $\mathrm{AC}$ is a tangent to the log-spiral curve at point $\mathrm{C}$; hence there is no velocity discontinuity along $\mathrm{BC}$.

9. The radial shear zone BCD may be considered to be composed of a sequence of rigid triangles, as in the investigations by $\mathrm{Chen}^{6}$ using the symmetrical Hill and Prandtl's mechanisms. All the small triangles move as rigid bodies in directions which make an angle $\phi$ with the discontinuity line $\mathrm{CD}$. The velocity of each small triangle is determined by the condition that the relative velocity between the triangles in contact has the direction which makes an angle $\phi$ to the contact surface. It has been shown ${ }^{6}$ that the velocity $V$ of each triangle is $V(\theta)=V_{1} \exp (\theta \tan \phi)$. The log-spiral curve $\mathrm{CD}$ is assumed to be tangent to line $\mathrm{DE}$ at $\mathrm{D}$; hence there is no velocity discontinuity along line $\mathrm{BD}$.

10. Finally, the triangular wedge BDE is assumed to be rigid, moving with velocity $V_{2}=V(\beta)=V_{1} \exp (\beta \tan \phi)$. Therefore, the velocities so determined constitute a kinematically admissible velocity field. Having established the velocity field of the kinematically admissible failure mechanism, the different terms of the work equation can be calculated as described below.

\section{Calculations of incremental external} work. The incremental external work due to an external force is the external force multiplied by the corresponding incremental displacement or velocity. The incremental external work due to self-weight in a region is the vertical component of the velocity in that region multiplied by the weight of the region. As shown in Fig. 2, the external forces contributing to the incremental

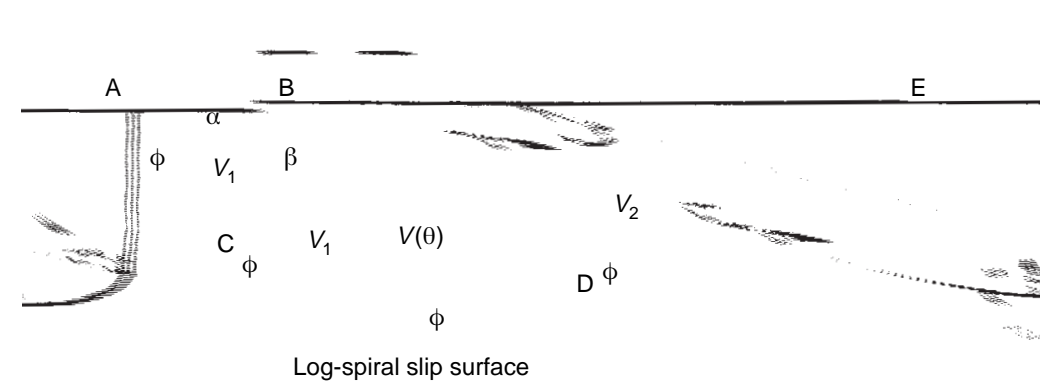

Fig. 1. Failure mechanism M1 for seismic bearing capacity analysis

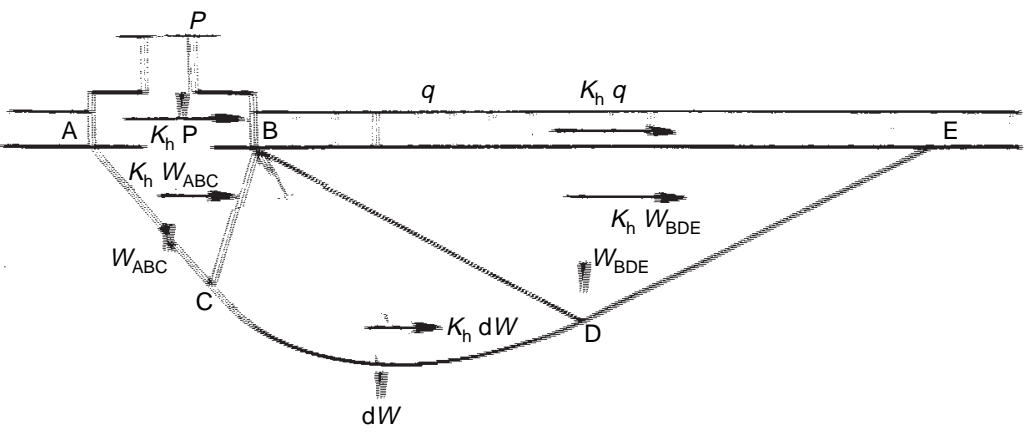

external work consist of the foundation load, the weight of the soil mass, the surcharge $q$ on the foundation level and the different inertia forces. These inertia forces concern the base shear load and the inertia forces of the soil mass and the surcharge loadings. The incremental external work for the different external forces can be easily obtained; the calculations are presented in Appendix 1.

12. Calculations of incremental internal energy dissipation. The incremental energy dissipation per unit length along a velocity discontinuity or a narrow transition zone can be expressed as

$$
\Delta D_{\mathrm{L}}=c \Delta V \cos \phi
$$

where $\Delta V$ is the incremental displacement or velocity which makes an angle $\phi$ with the velocity discontinuity according to the associated flow rule of perfect plasticity, and $c$ is the cohesion parameter. Calculations of the incremental energy dissipation along the different velocity discontinuities are given in Appendix 1.

13. Work equation. By equating the total external work (equation (24), Appendix 1) to the total internal energy dissipation (equation (32), Appendix 1), we have

$$
q_{\mathrm{c}}=\frac{P}{B_{0}}=\gamma \frac{B_{0}}{2} N_{\gamma \mathrm{E}}+c N_{\mathrm{cE}}+q N_{\mathrm{qE}}
$$

where $N_{\gamma \mathrm{E}}, N_{\mathrm{cE}}$ and $N_{\mathrm{qE}}$ are the seismic bearing capacity factors. They are given as follows
Fig. 2. Free body diagram for the $M 1$ mechanism 


$$
\begin{aligned}
N_{\gamma \mathrm{E}}= & -\frac{1}{\cos \alpha+K_{\mathrm{h} \sin \alpha}} \\
& \times\left[f_{1}+f_{3}+f_{5}+K_{\mathrm{h}}\left(f_{2}+f_{4}+f_{6}\right)\right] \\
N_{\mathrm{cE}}= & \frac{1}{\cos \alpha+K_{\mathrm{h}} \sin \alpha}\left(f_{9}+f_{10}+2 f_{11}\right) \\
N_{\mathrm{qE}}= & -\frac{1}{\cos \alpha+K_{\mathrm{h}} \sin \alpha}\left(f_{7}+K_{\mathrm{h}} f_{8}\right)
\end{aligned}
$$

\section{M2 mechanism}

14. As shown in Fig. 3, this mechanism is composed of a triangular active wedge $\mathrm{ABC}$, a radial circular shear zone $\mathrm{BCD}$ and a triangular passive wedge BDE. It is an arc-sandwich mechanism and will be referred to here as the M2 mechanism. As in the case of the M1 mechanism, the circular slip surface $\mathrm{CD}$ is assumed to be tangent to lines $\mathrm{AC}$ and $\mathrm{DE}$ at $\mathrm{C}$ and $\mathrm{D}$ respectively; hence there are no velocity discontinuities along $\mathrm{BC}$ and $\mathrm{BD}$. This mechanism is defined by the two angular parameters $\alpha$ and $\beta$.

15. The triangular wedge $\mathrm{ABC}$ is assumed to be rigid. It moves with velocity $V_{1}$, which makes an angle $\phi$ with the discontinuity line AC. The foundation is assumed to move with the same velocity as the wedge $\mathrm{ABC}$ (i.e. $V_{1}$ ). The centre of the circular arc $\mathrm{CD}$ is at point $\mathrm{B}$ and the radius $r_{0}$ is the length of the line $\mathrm{BC}$. It has been shown ${ }^{6}$ that the velocity $V$ along the circular shear zone is $V(\theta)=V_{1} \exp (\theta \tan 2 \phi)$.

16. Finally, the triangular wedge BDE is assumed to be rigid, moving with velocity $V_{2}=V(\beta)=V_{1} \exp (\beta \tan 2 \phi)$. Therefore, the velocities so determined constitute a kinematically admissible velocity field. Having established the velocity field of the kinematically admissible failure mechanism, the different terms of the work equation can be calculated; these calculations are presented in Appendix 2. As with the M1 mechanism, by equating the rate of the total external work (equation (46), Appendix 2) to the rate of the total internal energy dissipation (equation (54), Appendix 2), we obtain equation (2), where the seismic bearing capacity factors are given as follows

$$
\begin{aligned}
N_{\gamma \mathrm{E}}= & -\frac{1}{\cos (\alpha+\phi)+K_{\mathrm{h}} \sin (\alpha+\phi)} \\
& \times\left[g_{1}+g_{3}+g_{5}+K_{\mathrm{h}}\left(g_{2}+g_{4}+g_{6}\right)\right]
\end{aligned}
$$

$$
\begin{aligned}
& N_{\mathrm{cE}}=\frac{1}{\cos (\alpha+\phi)+K_{\mathrm{h}} \sin (\alpha+\phi)} \\
& \times\left[g_{9}+g_{10}+g_{11}+g_{12}\right] \\
& N_{\mathrm{qE}}=-\frac{1}{\cos (\alpha+\phi)+K_{\mathrm{h}} \sin (\alpha+\phi)} \\
& \times\left[g_{7}+K_{\mathrm{h}} g_{8}\right]
\end{aligned}
$$

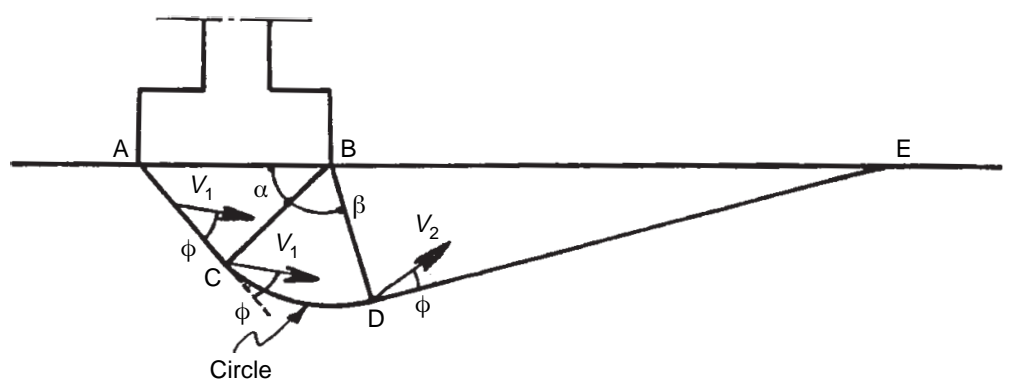

\section{Numerical results}

17. The most critical bearing capacity can be obtained by minimization of $q_{\mathrm{c}}$ (equation (2)) with respect to the parameters $\alpha$ and $\beta$. A computer program for assessing the seismic bearing capacity has been developed based on equation (2). The program gives the critical slip surface and the corresponding critical bearing capacity. In the following sections we present the bearing capacity factors for the two mechanisms M1 and M2 obtained from the numerical extremization of equations (3) to (8). The results are then compared with those of other authors for both static and seismic conditions.

\section{Static case}

18. The problem of bearing capacity in nonseismic areas has been widely treated in the literature by considering symmetrical failure mechanisms and using the limit equilibrium, the limit analysis or the slip line method.

19. $N_{c S}$ and $N_{q S}$ factors. For the $N_{\mathrm{cS}}$ and $N_{\mathrm{qS}}$ factors, it should be noted that the exact solution is well described in the literature ${ }^{6}$ and is given as

$$
\begin{aligned}
& N_{\mathrm{qS}}=\mathrm{e}^{\pi \tan \phi} \tan ^{2}\left(\frac{\pi}{4}+\frac{\phi}{2}\right) \\
& N_{\mathrm{cS}}=\left(N_{\mathrm{qS}}-1\right) \cot \phi
\end{aligned}
$$

20. Table 1 compares the $N_{\mathrm{qS}}$ and $N_{\mathrm{cS}}$ values obtained from the two proposed mechanisms with those of Terzaghi, ${ }^{1}$ Meyerhof, ${ }^{2}$ Sokolovski, ${ }^{3}$ Prakash and Saran, ${ }^{4}$ Saran ${ }^{5}$ and Saran and Agarwal. ${ }^{7}$ It should be mentioned here that the numerical bearing capacity factors $N_{\mathrm{qS}}$ and $N_{\mathrm{cS}}$ given by Sokolovski ${ }^{3}$ are the same as the ones given by the exact solutions (equations (9) and (10)). It is clear from Table 1 that the solutions of the $N_{\mathrm{qS}}$ and $N_{\mathrm{cS}}$ factors obtained from the M1 mechanism are the same as the exact solution given by equations (9) and (10). The corresponding critical slip surface obtained from the minimization procedure corresponds to $\alpha=\pi / 4+\phi / 2$ and $\beta=\pi / 2$, which means that lines $\mathrm{BD}$ and $\mathrm{DE}$ are inclined at an angle of $\pi / 4-\phi / 2$ to the horizontal direction, as it is the case of the symmetrical Prandtl mechanism (see below). Note, however, that the M2 mechanism greatly overestimates the $N_{\mathrm{qS}}$
Fig. 3. Failure mechanism M2 for seismic bearing capacity analysis 
Table 1. Comparison of static bearing capacity factors: (a) $N_{\mathrm{cS}}$; and (b) $N_{\mathrm{qS}}$

\begin{tabular}{|c|c|c|c|c|c|c|c|c|}
\hline $\begin{array}{l}\text { (a) } \\
\phi: \operatorname{deg}\end{array}$ & $\begin{array}{l}\text { Present } \\
\text { solution } \\
\text { M1 }\end{array}$ & $\begin{array}{l}\text { Present } \\
\text { solution } \\
\text { M2 }\end{array}$ & Terzaghi $^{1}$ & Meyerhof $^{2}$ & Sokolovski $^{3}$ & $\begin{array}{c}\text { Prakash and } \\
\text { Saran }\end{array}$ & $\operatorname{Saran}^{5}$ & $\begin{array}{l}\text { Saran and } \\
\text { Agarwal }^{7}\end{array}$ \\
\hline $\begin{array}{l}20 \\
30 \\
40\end{array}$ & $\begin{array}{l}14 \cdot 8 \\
30 \cdot 1 \\
75 \cdot 3\end{array}$ & $\begin{array}{l}18 \\
70 \\
-\end{array}$ & $\begin{array}{l}17 \cdot 7 \\
37 \cdot 2 \\
95 \cdot 7\end{array}$ & $\begin{array}{l}14 \cdot 5 \\
31 \\
73\end{array}$ & $\begin{array}{l}14 \cdot 8 \\
30 \cdot 1 \\
75 \cdot 3\end{array}$ & $\begin{array}{l}17 \cdot 3 \\
36 \cdot 6 \\
94 \cdot 8\end{array}$ & $\begin{array}{l}17 \cdot 5 \\
37 \cdot 2 \\
95 \cdot 4\end{array}$ & $\begin{array}{l}17 \cdot 7 \\
37 \cdot 2 \\
96\end{array}$ \\
\hline $\begin{array}{l}\text { (b) } \\
\phi: \operatorname{deg}\end{array}$ & $\begin{array}{l}\text { Present } \\
\text { solution } \\
\text { M1 }\end{array}$ & $\begin{array}{l}\text { Present } \\
\text { solution } \\
\text { M2 }\end{array}$ & Terzaghi ${ }^{1}$ & Meyerhof $^{2}$ & Sokolovski $^{3}$ & $\begin{array}{c}\text { Prakash and } \\
\text { Saran }\end{array}$ & $\operatorname{Saran}^{5}$ & $\begin{array}{l}\text { Saran and } \\
\text { Agarwal }^{7}\end{array}$ \\
\hline $\begin{array}{l}20 \\
30 \\
40\end{array}$ & $\begin{array}{r}6 \cdot 4 \\
18 \cdot 4 \\
64 \cdot 2\end{array}$ & $\begin{array}{r}7 \cdot 6 \\
41 \cdot 4 \\
-\end{array}$ & $\begin{array}{r}7 \cdot 4 \\
22 \cdot 5 \\
81 \cdot 3\end{array}$ & $\begin{array}{l}6 \cdot 8 \\
19 \cdot 5 \\
64\end{array}$ & $\begin{array}{r}6 \cdot 4 \\
18 \cdot 4 \\
64 \cdot 2\end{array}$ & $\begin{array}{r}7 \cdot 4 \\
22 \cdot 4 \\
81 \cdot 3\end{array}$ & $\begin{array}{r}7 \cdot 4 \\
22 \cdot 5 \\
81 \cdot 3\end{array}$ & $\begin{array}{r}7 \cdot 4 \\
22 \cdot 5 \\
81 \cdot 6\end{array}$ \\
\hline
\end{tabular}

and $N_{\mathrm{cS}}$ values, especially for large $\phi$ values, and equation (10) is still satisfied for this mechanism.

21. $N_{\gamma \mathrm{S}}$ factor. For the $N_{\gamma \mathrm{S}}$ values, many solutions are proposed in the literature based on different failure mechanisms. Chen ${ }^{6}$ considered three symmetrical failure mechanisms referred to as Prandtl1, Prandtl2 and Prandtl3 and gave rigorous upper-bound solutions for the three mechanisms in the framework of the limit analysis theory. Prandtl1 is composed of a triangular active wedge under the footing, two radial log-spiral shear zones and two triangular passive wedges. Prandtl2 differs from Prandtl1 only in that an additional rigid body zone has been introduced. Finally, Prandtl3 resembles closely the Prandtl1 mechanism; however, each shear zone is now bounded by a circular arc.

22. Soubra and Reynolds ${ }^{11}$ and Soubra ${ }^{13,14}$ considered one-sided non-symmetrical mechanisms and developed upper-bound solutions for the bearing capacity problem. While Soubra and Reynolds ${ }^{1 \mathrm{P}}$ used a rotational log-spiral mechanism, Soubra ${ }^{13,14}$ used translational mechanisms. One mechanism ${ }^{14}$ is of the Coulomb type (two triangular wedges), whereas the other ${ }^{13}$ is composed of a triangular active wedge and a radial log-spiral shear zone. The latter mechanism is described by a single parameter. The mechanisms M1 and M2 presented in this paper are more general mechanisms since they are described by the two parameters $\alpha$ and $\beta$ and they permit a greater freedom for the slip surface to develop, thus leading to smaller upper-bound solutions of the bearing capacity problem.

23. Table 2 compares the $N_{\gamma \mathrm{S}}$ values obtained from the two proposed mechanisms with those of Chen, ${ }^{6}$ Soubra and Reynolds, ${ }^{11}$ and Soubra. ${ }^{13,14}$ It is clear from this table that the solutions of the $N_{\gamma \mathrm{S}}$ factor obtained from the M1 non-symmetrical mechanism are very close to the ones obtained from the Prandtl2 symmetrical mechanism. The critical slip surface corresponds to the case when lines $\mathrm{BD}$ and $\mathrm{DE}$ are inclined at an angle of $\pi / 4-\phi / 2$ to the horizontal direction. Note also that the results given by the M2 non-symmetrical mechanism are in good agreement with the ones given by the symmetrical Prandtl3 mechanism up to $\phi=30^{\circ}$.

24. Few of the available bearing capacity theories for a non-symmetrical mechanism ${ }^{10,15,16}$ belong to the limit equilibrium method or the slip line methods and we cannot say if the solutions they give are upper- or lower-bound ones with respect to the exact solution. However, as is well known in the framework of the limit analysis method, the exact solution of a bearing capacity problem can be bracketed by the minimal upper-bound

Table 2. Comparison of static bearing capacity factor $N_{\gamma \mathrm{S}}$ (upper-bound solutions)

\begin{tabular}{|c|c|c|c|c|c|c|c|c|}
\hline$\phi: \operatorname{deg}$ & $\begin{array}{l}\text { Present } \\
\text { solution } \\
\text { M1 }\end{array}$ & $\begin{array}{l}\text { Present } \\
\text { solution } \\
\text { M2 }\end{array}$ & $\begin{array}{c}\text { Chen }^{6} \\
\text { 'Prandtl1' }\end{array}$ & $\begin{array}{l}\text { Chen }{ }^{6} \\
\text { 'Prandtl2' }\end{array}$ & $\begin{array}{l}\text { Chen } \\
\text { 'Prandtl3' }\end{array}$ & $\begin{array}{l}\text { Soubra and } \\
\text { Reynolds }\end{array}$ & Soubra $^{13}$ & Soubra $^{14}$ \\
\hline 15 & $2 \cdot 3$ & $2 \cdot 1$ & $2 \cdot 7$ & $2 \cdot 3$ & $2 \cdot 1$ & $3 \cdot 2$ & $2 \cdot 4$ & $2 \cdot 5$ \\
\hline 20 & $5 \cdot 2$ & $4 \cdot 8$ & $5 \cdot 9$ & $5 \cdot 2$ & $4 \cdot 6$ & $7 \cdot 3$ & $5 \cdot 5$ & $5 \cdot 9$ \\
\hline 25 & $11 \cdot 4$ & $11 \cdot 1$ & $12 \cdot 4$ & $11 \cdot 4$ & $10 \cdot 9$ & $16 \cdot 5$ & $12 \cdot 1$ & $14 \cdot 1$ \\
\hline 30 & 25 & $31 \cdot 5$ & $26 \cdot 7$ & 25 & $31 \cdot 5$ & $38 \cdot 1$ & $26 \cdot 8$ & $36 \cdot 4$ \\
\hline 35 & $57 \cdot 1$ & $152 \cdot 2$ & $60 \cdot 2$ & 57 & 138 & $92 \cdot 5$ & $61 \cdot 6$ & $115 \cdot 6$ \\
\hline 40 & $140 \cdot 5$ & $5444 \cdot 4$ & 147 & 141 & 1803 & $243 \cdot 9$ & $152 \cdot 6$ & $642 \cdot 8$ \\
\hline
\end{tabular}


solution and the maximal lower-bound solution. Therefore, in this paper only the minimum value obtained by the different available upperbound methods (i.e. Chen, ${ }^{6}$ mechanism M1 or M2, Soubra and Reynolds ${ }^{11}$ or Soubra ${ }^{13,14}$ should be considered. It should be mentioned that the minimum results of the present nonsymmetrical mechanisms [Min (M1, M2)] give the lowest upper-bound solutions of the nonsymmetrical mechanisms available in the literature in the framework of the limit analysis theory (i.e. Soubra and Reynolds, ${ }^{11}$ and Soubra $\left.{ }^{13,14}\right)$. Note that in the following we will consider the minimal values of the two mechanisms M1 and M2 in order to provide the geotechnical engineer with the lowest upperbound solution.

25. For the sake of completeness, Table 3 compares the $N_{\gamma \mathrm{S}}$ values obtained with those of different authors using the limit equilibrium method and the slip line method (Terzaghi, ${ }^{1}$ Meyerhof, ${ }^{2}$ Sokolovski, ${ }^{3}$ Prakash and Saran, Saran, Sarma and Iossifelis, ${ }^{5}$ and Saran and Agarwal $^{7}$ ). It is generally known that Terzaghi's ${ }^{1}$ values give a conservative estimate. Experiments performed on models and at full scale by Muhs and Kahl, ${ }^{17}$ Feda, ${ }^{18}$ Selig and McKee, ${ }^{19}$ and De Beer ${ }^{20}$ showed that Terzaghi's analysis underestimates the bearing capacity. Saran ${ }^{5}$ showed by analysing model test data that the values of Terzaghi, ${ }^{1}$ Meyerhof ${ }^{2}$ and Sokolovski ${ }^{3}$ underestimate the $N_{\gamma \mathrm{S}}$ values. The present $N_{\gamma \mathrm{S}}$ values chosen as the minimal values of the M1 and M2 mechanisms are in good agreement with those of the non-symmetrical mechanism of Sarma and Iossifelis ${ }^{10}$ using the limit equilibrium method; the difference does not exceed 5\% when $\phi=40^{\circ}$.

26. Finally, one can easily see that in most cases M1 gives smaller values for the bearing capacity factors than $\mathrm{M} 2$, except for the $N_{\gamma \mathrm{S}}$ factor when $\phi<30^{\circ}$.

\section{Seismic case}

27. The analysis of the seismic bearing capacity problem by a pseudo-static approach, considering the inertia forces both on the soil mass and on the structure, has been undertaken by Sarma and Iossifelis, ${ }^{10}$ Soubra and Reynolds, ${ }^{11}$ Richards et al., ${ }^{15}$ and Soubra. ${ }^{13,14}$ While the analyses of Sarma and Iossifelis ${ }^{10}$ and of Richards et al. ${ }^{15}$ are based on the limit equilibrium method, the solutions presented by Soubra and Reynolds ${ }^{11}$ and Soubra ${ }^{13,14}$ are upper-bounds to the exact solution for an associated flow rule Coulomb material in the framework of the limit analysis theory.

28. Figure 4 shows the comparison of the present reduction factor $N_{\gamma \mathrm{E}} / N_{\gamma \mathrm{S}}$ obtained using the M1 mechanism with the one given by Dormieux and Pecker ${ }^{12}$ for $\phi=30^{\circ}$. The difference between the two curves is due to the fact that Dormieux and Pecker ${ }^{12}$ have limited the $\alpha$ parameter to $\pi / 2$ as mentioned in their paper. In fact, $\alpha<\pi / 2$ is valuable only for small values of $K_{\mathrm{h}}$; for greater values of $K_{\mathrm{h}}, \alpha$ becomes greater than $\pi / 2$. Table 4 presents the values of the angular parameters $\alpha$ and $\beta$ obtained from the numerical minimization by considering the restriction $\alpha<\pi / 2$ (Dormieux and Pecker ${ }^{12}$ ) and the unrestricted values from the present analysis. It is clear from this table that the difference with Dormieux and Pecker $^{12}$ appears when $K_{\mathrm{h}}=0 \cdot 25$, where $\alpha>\pi / 2$.

29. Tables 5 to 7 give the seismic bearing capacity factors $N_{\gamma \mathrm{E}}, N_{\mathrm{cE}}$ and $N_{\mathrm{qE}}$ from both the M1 and M2 mechanisms. As in the static case, in most cases M1 continues to give smaller values for the seismic bearing capacity factors than the M2 mechanism, except for the $N_{\gamma \mathrm{E}}$ factor when $\phi<30^{\circ}$. Furthermore, it should be mentioned that the present results
Fig. 4. Comparison of the present solution and that of Dormieux and Pecker ${ }^{12}$ for the M1 mechanism $\left(\phi=30^{\circ}\right)$

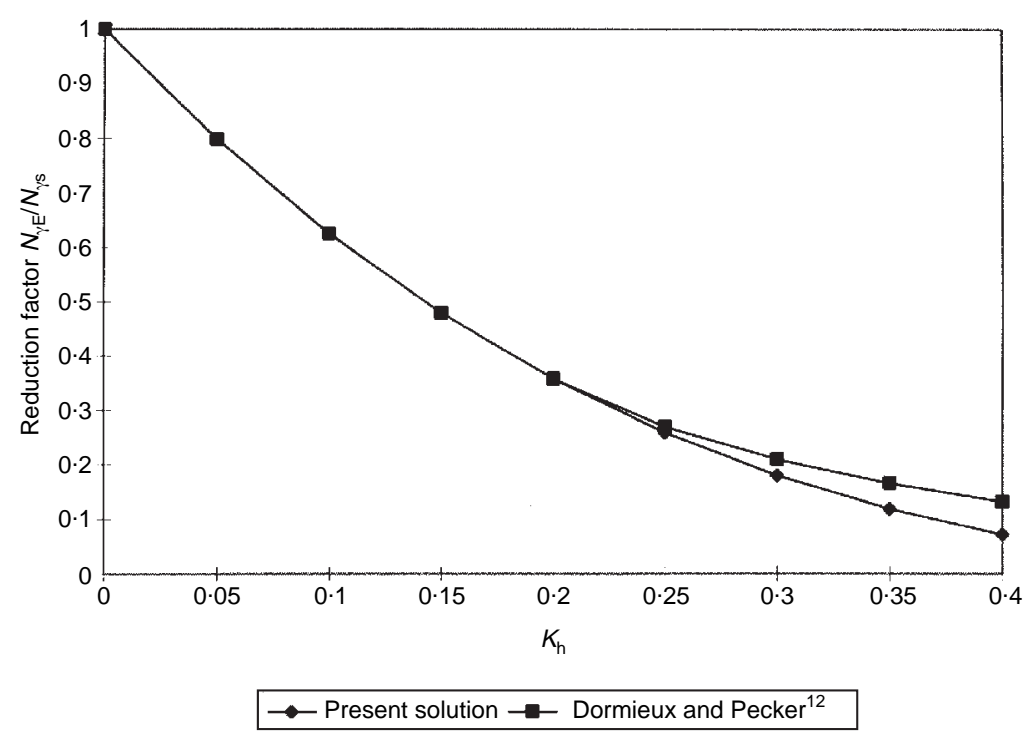

Table 3. Comparison of static bearing capacity factor $N_{\gamma \mathrm{S}}$ with available limit equilibrium and slip line methods

\begin{tabular}{c|c|c|c|c|c|c|c|c}
\hline$\phi:$ deg & $\begin{array}{c}\text { Present } \\
\text { solution } \\
\text { Min (M1, M2) }\end{array}$ & Terzaghi $^{1}$ & Meyerhof $^{2}$ & Sokolovski $^{3}$ & $\begin{array}{c}\text { Prakash and }_{4^{4}} \\
\text { Saran }\end{array}$ & Saran $^{5}$ & $\begin{array}{c}\text { Sarma and } \\
\text { Iossifelis }^{10}\end{array}$ & $\begin{array}{c}\text { Saran and } \\
\text { Agarwal }^{7}\end{array}$ \\
\hline 20 & $4 \cdot 8$ & 5 & $2 \cdot 8$ & $3 \cdot 2$ & $3 \cdot 8$ & 6 & $5 \cdot 7$ & $6 \cdot 4$ \\
30 & 25 & $19 \cdot 7$ & 16 & $15 \cdot 3$ & $19 \cdot 4$ & $29 \cdot 3$ & 25 & $29 \cdot 4$ \\
40 & $140 \cdot 5$ & $100 \cdot 4$ & 95 & $85 \cdot 3$ & $115 \cdot 8$ & $165 \cdot 3$ & $133 \cdot 8$ & $166 \cdot 1$ \\
\hline
\end{tabular}


Table 4. Comparison of the angular parameters $\alpha$ and $\beta$ as given by the present analysis and that of Dormieux and Pecker ${ }^{12}$ for $\phi=30^{\circ}$

\begin{tabular}{l|c|c|c|c|c|c}
\hline \multirow{2}{*}{$K_{\mathrm{h}}$} & \multicolumn{3}{|c|}{ Present solution } & \multicolumn{3}{c}{ Dormieux and Pecker } \\
\cline { 2 - 6 } & $\alpha: \operatorname{deg}$ & $\beta: \operatorname{deg}$ & $N_{\gamma \mathrm{E}}$ & $\alpha: \operatorname{deg}$ & $\beta: \operatorname{deg}$ & $N_{\gamma \mathrm{E}}$ \\
\hline 0 & $74 \cdot 74$ & $75 \cdot 26$ & $24 \cdot 98$ & $74 \cdot 74$ & $75 \cdot 26$ & $24 \cdot 98$ \\
$0 \cdot 05$ & $78 \cdot 56$ & $69 \cdot 49$ & $19 \cdot 95$ & $78 \cdot 56$ & $69 \cdot 49$ & $19 \cdot 95$ \\
$0 \cdot 1$ & $82 \cdot 39$ & $63 \cdot 74$ & $15 \cdot 63$ & $82 \cdot 39$ & $63 \cdot 74$ & $15 \cdot 63$ \\
$0 \cdot 15$ & $86 \cdot 24$ & $57 \cdot 98$ & $11 \cdot 97$ & $86 \cdot 24$ & $57 \cdot 98$ & $11 \cdot 97$ \\
$0 \cdot 2$ & $90 \cdot 09$ & $52 \cdot 23$ & $8 \cdot 94$ & $90 \cdot 00$ & $52 \cdot 23$ & $8 \cdot 94$ \\
$0 \cdot 25$ & $93 \cdot 92$ & $46 \cdot 47$ & $6 \cdot 47$ & $90 \cdot 00$ & $50 \cdot 52$ & $6 \cdot 74$ \\
$0 \cdot 3$ & $97 \cdot 76$ & $40 \cdot 69$ & $4 \cdot 50$ & $90 \cdot 00$ & $48 \cdot 69$ & $5 \cdot 25$ \\
$0 \cdot 35$ & $101 \cdot 52$ & $34 \cdot 83$ & $2 \cdot 97$ & $90 \cdot 00$ & $46 \cdot 79$ & $4 \cdot 16$ \\
$0 \cdot 4$ & $105 \cdot 38$ & $28 \cdot 94$ & $1 \cdot 81$ & $90 \cdot 00$ & $44 \cdot 76$ & $3 \cdot 31$ \\
\hline
\end{tabular}

Table 5. Seismic bearing capacity factor $N_{\gamma \mathrm{E}}$ from the M1 and M2 mechanisms

\begin{tabular}{c|l|l|l|c|c|c|c}
\hline \multirow{3}{*}{} & \multirow{2}{*}{$K_{\mathrm{h}}$} & \multicolumn{7}{|c}{$\phi: \operatorname{deg}$} \\
\cline { 3 - 7 } & & 15 & 20 & 25 & 30 & 35 & 40 \\
\hline \multirow{4}{*}{ M1 } & 0 & $2 \cdot 3$ & $5 \cdot 2$ & $11 \cdot 4$ & $25 \cdot 0$ & $57 \cdot 1$ & $140 \cdot 5$ \\
& $0 \cdot 1$ & $1 \cdot 1$ & $3 \cdot 0$ & $6 \cdot 9$ & $15 \cdot 6$ & $36 \cdot 1$ & $88 \cdot 4$ \\
& $0 \cdot 2$ & - & $1 \cdot 3$ & $3 \cdot 6$ & $8 \cdot 9$ & $21 \cdot 4$ & $53 \cdot 0$ \\
& $0 \cdot 3$ & - & - & $1 \cdot 5$ & $4 \cdot 5$ & $11 \cdot 7$ & $30 \cdot 1$ \\
& $0 \cdot 4$ & - & - & - & $1 \cdot 8$ & $5 \cdot 8$ & $16 \cdot 0$ \\
& $0 \cdot 5$ & - & - & - & - & $2 \cdot 3$ & $7 \cdot 8$ \\
& $0 \cdot 6$ & - & - & - & - & - & $3 \cdot 3$ \\
\hline \multirow{6}{*}{ M2 } & 0 & $2 \cdot 1$ & $4 \cdot 8$ & $11 \cdot 1$ & $31 \cdot 5$ & $152 \cdot 2$ & $5444 \cdot 4$ \\
& $0 \cdot 1$ & - & $2 \cdot 7$ & $6 \cdot 6$ & $18 \cdot 9$ & $85 \cdot 2$ & $2288 \cdot 7$ \\
& $0 \cdot 2$ & - & $1 \cdot 2$ & $3 \cdot 4$ & $10 \cdot 3$ & $44 \cdot 4$ & $912 \cdot 1$ \\
& $0 \cdot 3$ & - & - & $1 \cdot 4$ & $4 \cdot 9$ & $21 \cdot 3$ & $345 \cdot 1$ \\
& $0 \cdot 4$ & - & - & - & $1 \cdot 9$ & $9 \cdot 1$ & $123 \cdot 2$ \\
& $0 \cdot 5$ & - & - & - & - & $3 \cdot 3$ & $40 \cdot 6$ \\
& $0 \cdot 6$ & - & - & - & - & $0 \cdot 8$ & $11 \cdot 7$ \\
& $0 \cdot 7$ & - & - & - & - & - & $2 \cdot 5$ \\
\hline
\end{tabular}

Table 6. Seismic bearing capacity factor $N_{\mathrm{cE}}$ from the M1 and M2 mechanisms

\begin{tabular}{c|l|c|c|c|c|c|c}
\hline \multirow{3}{*}{} & \multirow{2}{*}{$K_{\mathrm{h}}$} & \multicolumn{7}{|c}{$\phi: \operatorname{deg}$} \\
\cline { 2 - 7 } & & 15 & 20 & 25 & 30 & 35 & 40 \\
\hline \multirow{6}{*}{ M1 } & 0 & $11 \cdot 0$ & $14 \cdot 8$ & $20 \cdot 7$ & $30 \cdot 1$ & $46 \cdot 1$ & $75 \cdot 3$ \\
& $0 \cdot 1$ & $9 \cdot 5$ & $12 \cdot 7$ & $17 \cdot 5$ & $25 \cdot 0$ & $37 \cdot 6$ & $60 \cdot 1$ \\
& $0 \cdot 2$ & $7 \cdot 9$ & $10 \cdot 5$ & $14 \cdot 3$ & $20 \cdot 3$ & $30 \cdot 0$ & $46 \cdot 9$ \\
& $0 \cdot 3$ & $6 \cdot 4$ & $8 \cdot 5$ & $11 \cdot 5$ & $16 \cdot 1$ & $23 \cdot 5$ & $36 \cdot 1$ \\
& $0 \cdot 4$ & $5 \cdot 1$ & $6 \cdot 7$ & $9 \cdot 1$ & $12 \cdot 6$ & $18 \cdot 1$ & $27 \cdot 4$ \\
& $0 \cdot 5$ & $4 \cdot 0$ & $5 \cdot 2$ & $7 \cdot 0$ & $9 \cdot 7$ & $13 \cdot 8$ & $20 \cdot 7$ \\
& $0 \cdot 6$ & $3 \cdot 0$ & $4 \cdot 0$ & $5 \cdot 4$ & $7 \cdot 4$ & $10 \cdot 5$ & $15 \cdot 5$ \\
& $0 \cdot 7$ & - & - & $4 \cdot 0$ & $5 \cdot 6$ & $7 \cdot 9$ & $11 \cdot 6$ \\
& $0 \cdot 8$ & - & - & - & $4 \cdot 2$ & $5 \cdot 9$ & $8 \cdot 7$ \\
& $0 \cdot 9$ & - & - & - & $3 \cdot 1$ & $4 \cdot 4$ & $6 \cdot 5$ \\
& 1 & - & - & - & - & $3 \cdot 3$ & $4 \cdot 9$ \\
\hline \multirow{6}{*}{ M2 } & 0 & $11 \cdot 9$ & $18 \cdot 0$ & $31 \cdot 3$ & $70 \cdot 0$ & $280 \cdot 6$ & - \\
& $0 \cdot 1$ & $10 \cdot 2$ & $15 \cdot 1$ & $25 \cdot 3$ & $53 \cdot 7$ & $193 \cdot 8$ & - \\
& $0 \cdot 2$ & $8 \cdot 5$ & $12 \cdot 3$ & $19 \cdot 9$ & $40 \cdot 1$ & $130 \cdot 7$ & - \\
& $0 \cdot 3$ & $6 \cdot 8$ & $9 \cdot 7$ & $15 \cdot 3$ & $29 \cdot 2$ & $86 \cdot 4$ & - \\
& $0 \cdot 4$ & $5 \cdot 3$ & $7 \cdot 5$ & $11 \cdot 4$ & $20 \cdot 9$ & $56 \cdot 3$ & - \\
& $0 \cdot 5$ & $4 \cdot 1$ & $5 \cdot 6$ & $8 \cdot 4$ & $14 \cdot 7$ & $36 \cdot 1$ & - \\
& $0 \cdot 6$ & - & $4 \cdot 1$ & $6 \cdot 0$ & $10 \cdot 1$ & $22 \cdot 9$ & - \\
& $0 \cdot 7$ & - & - & $4 \cdot 2$ & $6 \cdot 8$ & $14 \cdot 2$ & - \\
& $0 \cdot 8$ & - & - & - & - & $8 \cdot 6$ & - \\
\hline
\end{tabular}


Table 7. Seismic bearing capacity factor $N_{\mathrm{qE}}$ from the M1 and M2 mechanisms

\begin{tabular}{c|c|c|c|c|c|c|c}
\hline \multirow{3}{*}{} & \multirow{2}{*}{$K_{\mathrm{h}}$} & \multicolumn{7}{c}{$\phi: \operatorname{deg}$} \\
\cline { 3 - 7 } & & 15 & 20 & 25 & 30 & 35 & 40 \\
\hline \multirow{6}{*}{ M1 } & 0 & $3 \cdot 9$ & $6 \cdot 4$ & $10 \cdot 7$ & $18 \cdot 4$ & $33 \cdot 3$ & $64 \cdot 2$ \\
& $0 \cdot 1$ & $3 \cdot 1$ & $5 \cdot 0$ & $8 \cdot 3$ & $14 \cdot 3$ & $25 \cdot 6$ & $48 \cdot 7$ \\
& $0 \cdot 2$ & $2 \cdot 1$ & $3 \cdot 6$ & $6 \cdot 2$ & $10 \cdot 7$ & $19 \cdot 0$ & $35 \cdot 9$ \\
& $0 \cdot 3$ & - & $2 \cdot 2$ & $4 \cdot 2$ & $7 \cdot 5$ & $13 \cdot 6$ & $25 \cdot 7$ \\
& $0 \cdot 4$ & - & - & $2 \cdot 5$ & $5 \cdot 0$ & $9 \cdot 4$ & $17 \cdot 9$ \\
& $0 \cdot 5$ & - & - & - & - & $6 \cdot 0$ & $12 \cdot 0$ \\
& $0 \cdot 6$ & - & - & - & - & $3 \cdot 5$ & $7 \cdot 7$ \\
& $0 \cdot 7$ & - & - & - & - & - & $4 \cdot 6$ \\
\hline \multirow{6}{*}{ M2 } & 0 & $4 \cdot 2$ & $7 \cdot 6$ & $15 \cdot 6$ & $41 \cdot 4$ & $197 \cdot 5$ & - \\
& $0 \cdot 1$ & $3 \cdot 2$ & $5 \cdot 7$ & $11 \cdot 5$ & $29 \cdot 1$ & $125 \cdot 0$ & - \\
& $0 \cdot 2$ & $2 \cdot 1$ & $4 \cdot 0$ & $8 \cdot 0$ & $19 \cdot 5$ & $76 \cdot 2$ & - \\
& $0 \cdot 3$ & - & $2 \cdot 4$ & $5 \cdot 1$ & $12 \cdot 4$ & $44 \cdot 6$ & - \\
& $0 \cdot 4$ & - & - & - & $7 \cdot 3$ & $24 \cdot 9$ & - \\
& $0 \cdot 5$ & - & - & - & $3 \cdot 6$ & $13 \cdot 0$ & - \\
& $0 \cdot 6$ & - & - & - & - & $5 \cdot 8$ & - \\
\hline
\end{tabular}

[Min (M1, M2)] give the lowest upper-bound solutions of the non-symmetrical mechanisms available in the literature in the framework of the limit analysis theory. $11,13,14$

30. Figure 5 shows the variation of the seismic $N_{\gamma \mathrm{E}}$ value with the horizontal seismic coefficient $K_{\mathrm{h}}$ when $\phi=30^{\circ}$, as given by the present analysis, Sarma and Iossifelis ${ }^{10}$ and Richards et al. ${ }^{15}$ The comparison of the present upper-bound solution with the solutions presented by Sarma and Iossifelis ${ }^{10}$ and Richards et al. ${ }^{15}$ in the framework of the limit equilibrium method shows good agreement. The maximum difference does not exceed 13\% when compared with Sarma and Iossifelis ${ }^{10}$ results and 6\% compared with Richards et al. ${ }^{15}$

31. Figures 6 to 8 show design charts of the seismic bearing capacity factors as given by the present analysis for $\phi=20^{\circ}, 25^{\circ}, 30^{\circ}, 35^{\circ}$ and $40^{\circ}$. In these figures the values proposed by Sarma and Iossifelis ${ }^{10}$ for the same $\phi$ values and those proposed by Richards et al. ${ }^{15}$ for $\phi=20^{\circ}, 30^{\circ}$ and $40^{\circ}$ are also presented. These figures again confirm the agreement of the present results with those of these authors for the different values of $\phi$ and $K_{\mathrm{h}}$, except for the $N_{\text {cE }}$ value proposed by Richards et al. ${ }^{15}$ This may be explained by the fact that Richards et al. ${ }^{15}$ have used equation (10) to calculate the seismic factor $N_{\mathrm{cE}}$ without any real justification, as they mentioned in their paper.

32. Figure 9 shows the variation of $N_{\gamma \mathrm{E}} / N_{\gamma \mathrm{S}}$ with $K_{\mathrm{h}}$ for $\phi=35^{\circ}$, according to the present analysis (Sarma and Iossifelis, ${ }^{10}$ Soubra and Reynolds, ${ }^{11}$ Soubra, ${ }^{13,14}$ Richards et al. ${ }^{15}$ and Budhu and Al-Karni ${ }^{16}$ ). It can easily be seen that the present solutions in terms of the reduction in the $N_{\gamma \mathrm{E}}$ factor agree well with the ones of Richards et al. ${ }^{15}$ and Sarma and Iossifelis, ${ }^{10}$ as was shown in Fig. 5. For the $\phi$ value used in Fig. $9\left(\phi=35^{\circ}\right)$, this agreement is best with the results of Richards et al. ${ }^{15}$

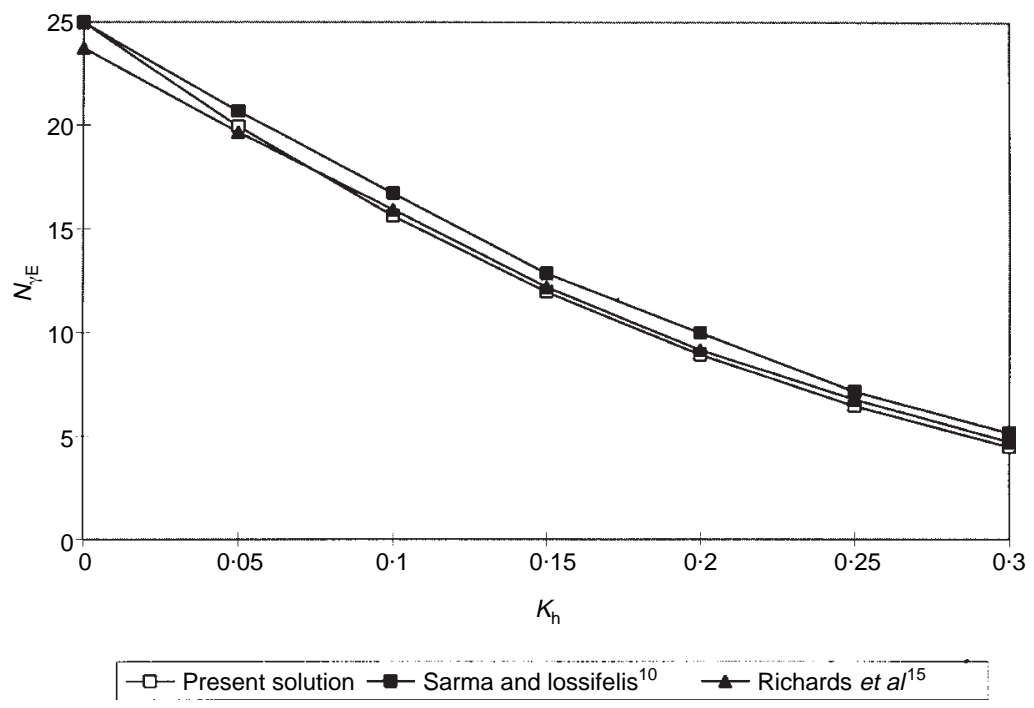

Fig. 5. Variation of the seismic bearing capacity factor $N_{\gamma \mathrm{E}}$ with $K_{\mathrm{h}}$ as given by different authors $\left(\phi=30^{\circ}\right)$

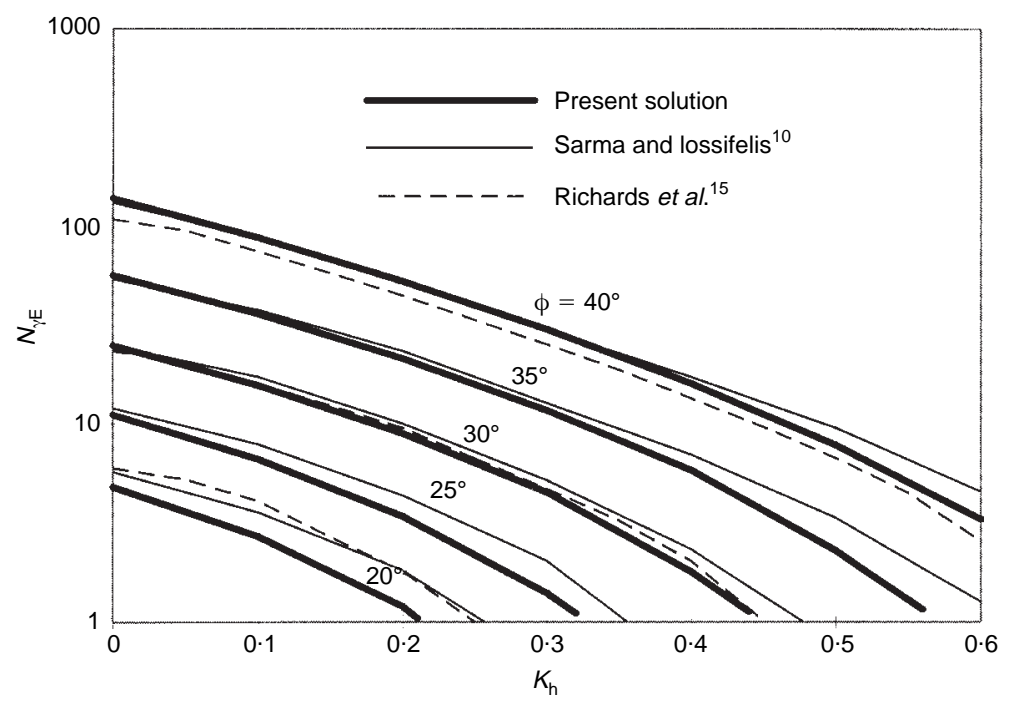

Fig. 6. Design charts for $N_{\gamma \mathrm{E}}$ 
33. Finally, it should be mentioned that the seismic acceleration generated by earthquakes not only imposes extra loadings on a soil mass but also shifts the sliding surface to less favourable positions. Fig. 10 shows that the critical slip surface of the M1 mechanism becomes shallower as the acceleration intensity increases. This conforms with the results of Richards et al. $^{15}$

\section{Conclusions}

34. Two failure mechanisms have been considered for the analysis of the seismic bearing capacity factors using the upper-bound method in limit analysis. The solutions presented are rigorous upper-bound ones in the framework of the limit analysis theory for an associated flow rule Coulomb material. The numerical results obtained lead to the following conclusions.

(a) For the static case, the log-sandwich mechanism M1 gives the exact solutions of the $N_{\mathrm{cS}}$ and $N_{\mathrm{qS}}$ factors. The angular parameters obtained from the numerical minimization show that the passive triangular wedge is in a passive Rankine state, as it is in the case of the symmetrical Prandtl mechanism. However, the arc-sandwich mechanism M2 gives non-interesting results in this case since one obtains higher upperbound solutions than the former mechanism. For the $N_{\gamma \mathrm{S}}$ factor, it was found that the results of the M1 mechanism are very close to the ones of the symmetrical failure mechanism Prandt1 2 considered by Chen ${ }^{6}$ using the limit analysis method, and that the critical failure mechanism corresponds to the case when the passive wedge is in a Rankine state. However, the M2 mechanism gives results which are very close to another symmetrical mechanism, Prandtl3, ${ }^{6}$ up to $\phi=30^{\circ}$. For design purposes, one has

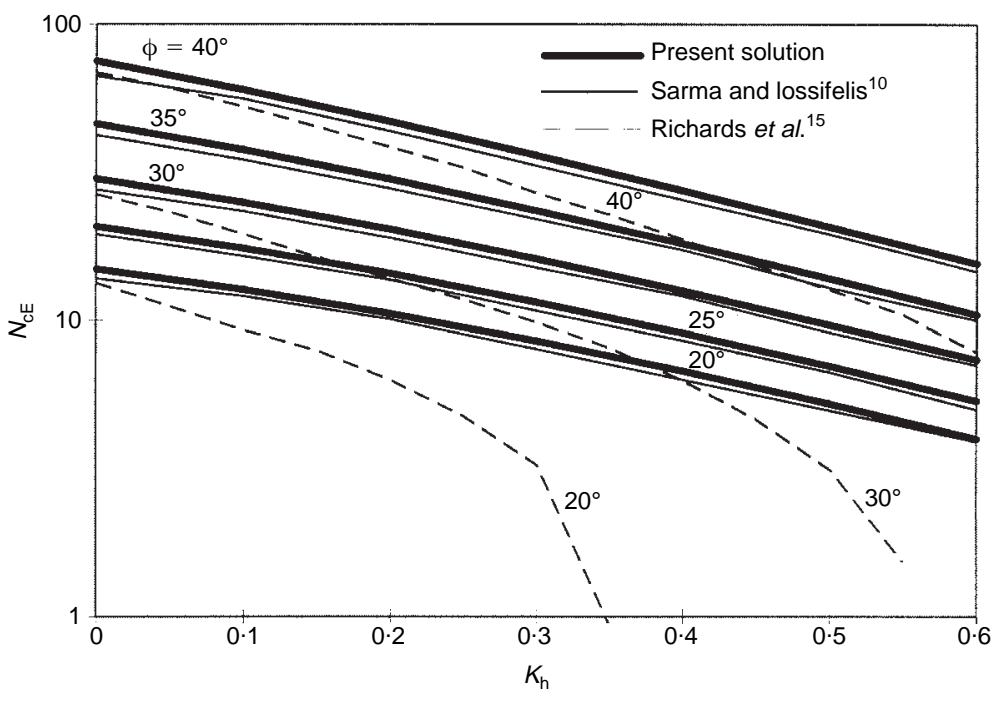

Fig. 7. Design charts for $N_{\mathrm{cE}}$

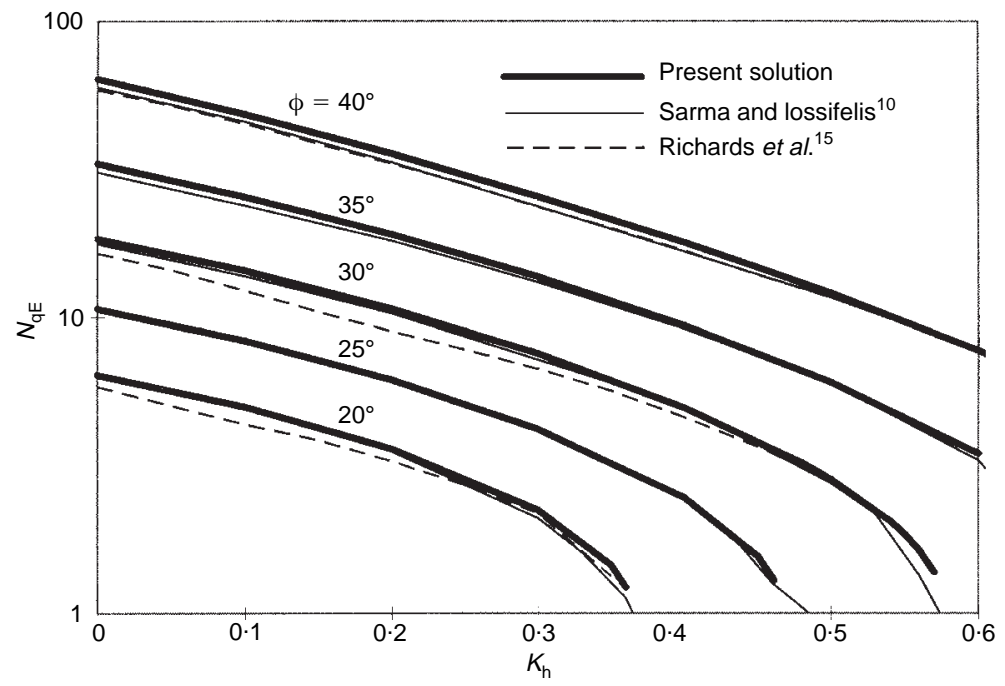

Fig. 8. Design charts for $N_{\mathrm{qE}}$

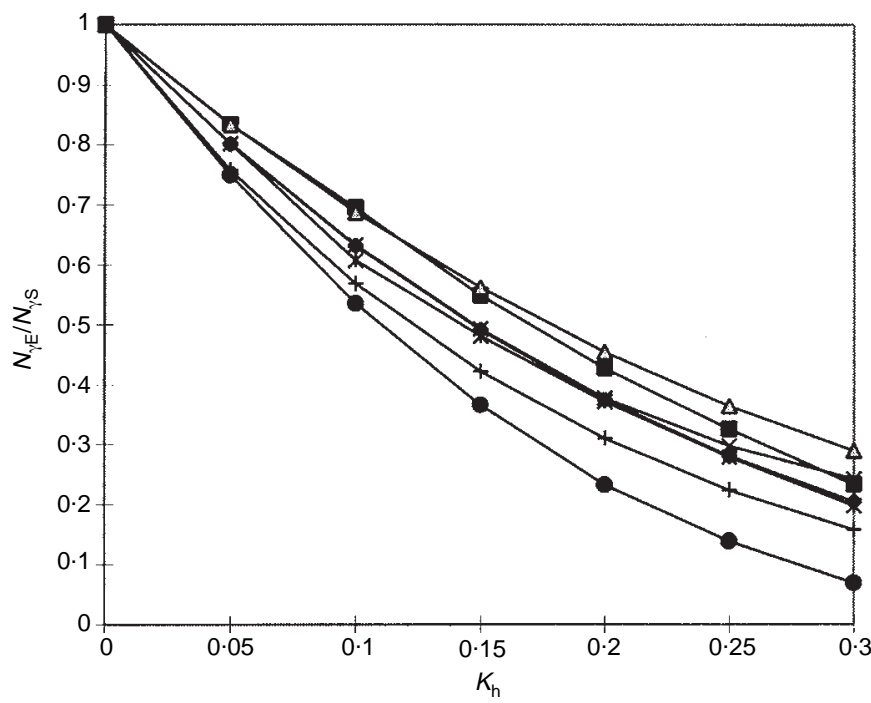

Fig. 9. Variation of $N_{\gamma \mathrm{E}} / N_{\gamma \mathrm{S}}$ with $K_{\mathrm{h}}$ as given by different authors $\left(\phi=35^{\circ}\right)$ 


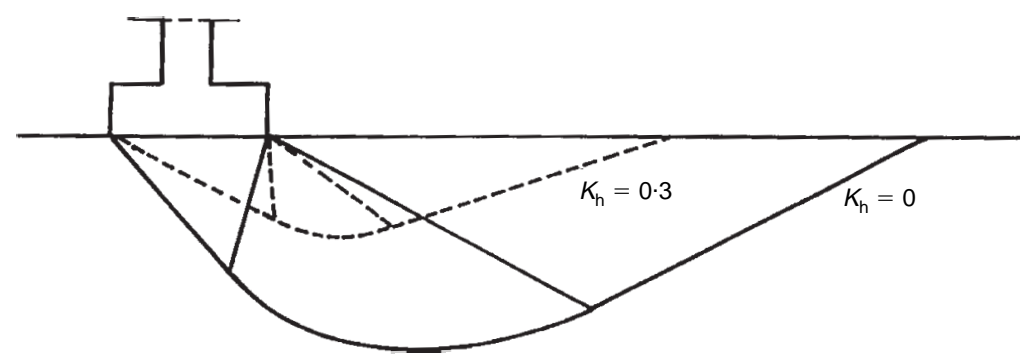

Fig. 10. Critical slip surfaces from the $M 1 \log$-sandwich mechanism $\left(\phi=35^{\circ}\right)$

to choose the minimal value from both the M1 and M2 mechanisms [Min (M1, M2)]. Note that the lowest upper-bound solutions are obtained from the M1 mechanism when $\phi>30^{\circ}$ and from the M2 mechanism when $\phi<30^{\circ}$. The present upper-bound solutions [Min (M1, M2)] are smaller than the ones available in the literature for non-symmetrical failure mechanisms in the framework of the upper-bound method of limit analysis theory.

(b) For the seismic case, in most cases the logsandwich M1 mechanism continues to give smaller values for the seismic bearing capacity factors than the arc-sandwich M2 mechanism, except for the $N_{\gamma \mathrm{E}}$ factor when $\phi<30^{\circ}$. For design purposes, one has to choose the minimal values from both mechanisms. It should be mentioned that the present upper-bound solutions for the seismic bearing capacity factors are the smallest ones with respect to the results available in the literature in the framework of the kinematical method of limit analysis. Furthermore, the present results for the seismic bearing capacity factors are in good agreement with the ones of Sarma and Iossifelis ${ }^{10}$ and Richards et al. ${ }^{15}$ using the limit equilibrium method. These results are presented in the form of design charts for practical use.

\section{Appendix 1}

35. In this appendix, we present the different expressions for the incremental external work of the different regions of mechanism M1, together with the internal energy dissipation for the same mechanism.

\section{Incremental external work}

36. The different elements of the incremental external work for the M1 mechanism can be calculated as follows.

(a) Incremental external work due to self-weight and inertia force of triangle $\mathrm{ABC}$

$\Delta W_{\mathrm{ABC}}=\frac{\gamma B_{0}^{2}}{2}\left[f_{1}(\alpha, \beta)+K_{\mathrm{h}} f_{2}(\alpha, \beta)\right] V_{1}$

where

$f_{1}=\frac{\sin 2 \alpha \cos (\alpha-\phi)}{2 \cos \phi}$

$$
f_{2}=\frac{\sin 2 \alpha \tan \alpha \cos (\alpha-\phi)}{2 \cos \phi}
$$

(b) Incremental external work due to self-weight and inertia force of the radial shear zone BCD

$\Delta W_{\mathrm{BCD}}=\frac{\gamma B_{0}^{2}}{2}\left[f_{3}(\alpha, \beta)+K_{\mathrm{h}} f_{4}(\alpha, \beta)\right] V_{1}$

where

$$
\begin{gathered}
f_{3}=\frac{\cos ^{2}(\alpha-\phi)}{\cos ^{2} \phi} \times \\
\mathrm{e}^{3 \beta \tan \phi}\left\{\frac{[3 \tan \phi \cos (\alpha+\beta)+\sin (\alpha+\beta)]}{1+9 \tan ^{2} \phi}\right. \\
\left.-\frac{[-3 \tan \phi \cos \alpha-\sin \alpha]}{1+9 \tan ^{2} \phi}\right\} \\
f_{4}=\frac{\cos ^{2}(\alpha-\phi)}{\cos ^{2} \phi} \times \\
\mathrm{e}^{3 \beta \tan \phi}\left\{\frac{[3 \tan \phi \sin (\alpha+\beta)-\cos (\alpha+\beta)]}{1+9 \tan ^{2} \phi}\right. \\
\left.\frac{-[3 \tan \phi \sin \alpha+\cos \alpha]}{1+9 \tan ^{2} \phi}\right\}
\end{gathered}
$$

(c) Incremental external work due to self-weight and inertia force of triangle $\mathrm{BDE}$

$\Delta W_{\mathrm{BDE}}=\frac{\gamma B_{0}^{2}}{2}\left[f_{5}(\alpha, \beta)+K_{\mathrm{h}} f_{6}(\alpha, \beta)\right] V_{1}$

where

$f_{5}=-\frac{\cos (\alpha+\beta) \sin (\alpha+\beta) \cos ^{2}(\alpha-\phi)}{\cos (\alpha+\beta-\phi) \cos \phi} \mathrm{e}^{3 \beta \tan \phi}$

$f_{6}=-\frac{\cos ^{2}(\alpha-\phi) \sin ^{2}(\alpha+\beta)}{\cos (\alpha+\beta-\phi) \cos \phi} \mathrm{e}^{3 \beta \tan \phi}$

(d) Incremental external work due to the foundation load and the corresponding inertia force

$\Delta W_{\mathrm{P}}=P\left(\cos \alpha+K_{\mathrm{h}} \sin \alpha\right) V_{1}$

(e) Incremental external work due to the surcharge loading and the corresponding inertia force

$\Delta W_{\mathrm{q}}=q B_{0}\left[f_{7}(\alpha, \beta)+K_{h} f_{8}(\alpha, \beta)\right] V_{1}$

where

$$
\begin{aligned}
& f_{7}=-\frac{\cos \alpha \cos (\alpha-\phi) \cos (\alpha+\beta)}{\cos (\alpha+\beta-\phi)} \mathrm{e}^{2 \beta \tan \phi} \\
& f_{8}=-\frac{\cos (\alpha-\phi) \sin (\alpha+\beta)}{\cos (\alpha+\beta-\phi)} \mathrm{e}^{2 \beta \tan \phi}
\end{aligned}
$$

37. The total incremental external work is the summation of these five contributions; that is, equations (11), (14), (17), (20) and (21)

$$
\begin{aligned}
& \Sigma[\Delta W]_{\mathrm{ext}}= \\
& \Delta W_{\mathrm{ABC}}+\Delta W_{\mathrm{BCD}}+\Delta W_{\mathrm{BDE}}+\Delta W_{\mathrm{P}}+\Delta W_{\mathrm{q}}
\end{aligned}
$$


Incremental internal energy dissipation

38. The different elements of the incremental internal energy dissipation for the M1 mechanism can be calculated as follows.

(a) Along AC

$\Delta D_{\mathrm{AC}}=c B_{0} f_{9}(\alpha, \beta) V_{1}$

where

$f_{9}=\sin \alpha$

(b) Along DE

$\Delta D_{\mathrm{DE}}=c B_{0} f_{10}(\alpha, \beta) V_{1}$

where

$f_{10}=-\frac{\sin (\alpha+\beta) \cos (\alpha-\phi)}{\cos (\alpha+\beta-\phi)} \mathrm{e}^{2 \beta \tan \phi}$

(c) Along $\mathrm{CD}$

$\Delta D_{\mathrm{CD}}=c B_{0} f_{11}(\alpha, \beta) V_{1}$

where

$f_{11}=\frac{\cos (\alpha-\phi)}{2 \sin \phi}\left(\mathrm{e}^{2 \beta \tan \phi}-1\right)$

(d) Along the radial lines of the shear zone BCD

$\Delta D_{\mathrm{rad}}=\Delta D_{\mathrm{CD}}$

39. The total incremental energy dissipation is the summation of these four parts: that is, equations (25), (27), (29) and (31)

$$
\Sigma[\Delta D]=\Delta D_{\mathrm{AC}}+\Delta D_{\mathrm{DE}}+\Delta D_{\mathrm{CD}}+\Delta D_{\mathrm{rad}}
$$

\section{Appendix 2}

40. In this appendix, we present the different expressions for the incremental external work of the different regions of mechanism M2, together with the internal energy dissipation for the same mechanism.

\section{Incremental external work}

41. The different elements of the incremental external work for the M2 mechanism can be calculated as follows.

(a) Incremental external work due to self-weight and inertia force of triangle $\mathrm{ABC}$

$\Delta W_{\mathrm{ABC}}=\frac{\gamma B_{0}^{2}}{2}\left[g_{1}(\alpha, \beta)+K_{\mathrm{h}} g_{2}(\alpha, \beta)\right] V_{1}$

where

$g_{1}=\frac{\sin 2 \alpha \cos (\alpha+\phi)}{2}$

$g_{2}=\frac{\sin 2 \alpha \sin (\alpha+\phi)}{2}$

(b) Incremental external work due to self-weight and inertia force of the radial shear zone BCD

$\Delta W_{\mathrm{BCD}}=\frac{\gamma B_{0}^{2}}{2}\left[g_{3}(\alpha, \beta)+K_{\mathrm{h}} g_{4}(\alpha, \beta)\right] V_{1}$

where

$$
\begin{aligned}
g_{3}= & \frac{\cos ^{2} \alpha}{1+\tan ^{2} 2 \phi}\left\{\mathrm{e}^{\beta \tan 2 \phi}\right. \\
& \times[\tan 2 \phi \cos (\alpha+\phi+\beta)+\sin (\alpha+\phi+\beta)] \\
& -[\tan 2 \phi \cos (\alpha+\phi)+\sin (\alpha+\phi)]\}
\end{aligned}
$$

$$
\begin{aligned}
g_{4}= & \frac{\cos ^{2} \alpha}{1+\tan ^{2} 2 \phi}\left\{\mathrm{e}^{\beta \tan 2 \phi}\right. \\
& \times[\tan 2 \phi \sin (\alpha+\phi+\beta)-\cos (\alpha+\phi+\beta)] \\
& -[\tan 2 \phi \sin (\alpha+\phi)-\cos (\alpha+\phi)]\}
\end{aligned}
$$

(c) Incremental external work due to self-weight and inertia force of triangle $\mathrm{BDE}$

$\Delta W_{\mathrm{BDE}}=\frac{\gamma B_{0}^{2}}{2}\left[g_{5}(\alpha, \beta)+K_{\mathrm{h}} g_{6}(\alpha, \beta)\right] V_{1}$

where

$g_{5}=-\frac{\cos ^{2} \alpha \sin (\alpha+\beta) \cos (\alpha+\beta+\phi)}{\cos (\alpha+\beta)} \mathrm{e}^{\beta \tan 2 \phi}$

$g_{6}=-\frac{\cos ^{2} \alpha \sin (\alpha+\beta) \sin (\alpha+\beta+\phi)}{\cos (\alpha+\beta)} \mathrm{e}^{\beta \tan 2 \phi}$

(d) Incremental external work due to the foundation load and the corresponding inertia force

$\Delta W_{\mathrm{P}}=P\left[\cos (\alpha+\phi)+K_{\mathrm{h}} \sin (\alpha+\phi)\right] V_{1}$

(e) Incremental external work due to the surcharge loading and the corresponding inertia force

$\Delta W_{\mathrm{q}}=q B_{0}\left[g_{7}(\alpha, \beta)+K_{h} g_{8}(\alpha, \beta)\right] V_{1}$

where

$$
\begin{aligned}
& g_{7}=-\frac{\cos \alpha \cos (\alpha+\beta+\phi)}{\cos (\alpha+\beta)} \mathrm{e}^{\beta \tan 2 \phi} \\
& g_{8}=-\frac{\cos \alpha \sin (\alpha+\beta+\phi)}{\cos (\alpha+\beta)} \mathrm{e}^{\beta \tan 2 \phi}
\end{aligned}
$$

42. The total incremental external work is the summation of these five contributions; that is, equations (33), (36), (39), (42) and (43)

$$
\begin{aligned}
\Sigma[\Delta W]_{\text {ext }}= & \Delta W_{\mathrm{ABC}}+\Delta W_{\mathrm{BCD}}+\Delta W_{\mathrm{BDE}} \\
& +\Delta W_{\mathrm{P}}+\Delta W_{\mathrm{q}}
\end{aligned}
$$

\section{Incremental internal energy dissipation}

43. The different elements of the incremental internal energy dissipation for the M2 mechanism can be calculated as follows.

(a) Along $\mathrm{AC}$

$\Delta D_{\mathrm{AC}}=c B_{0} g_{9}(\alpha, \beta) V_{1}$
where

$g_{9}=\sin \alpha \cos \phi$

(b) Along DE

$\Delta D_{\mathrm{DE}}=c B_{0} g_{10}(\alpha, \beta) V_{1}$

where

$g_{10}=-\frac{\cos \alpha \sin (\alpha+\beta) \cos \phi}{\cos (\alpha+\beta)} \mathrm{e}^{\beta \tan 2 \phi}$

(c) Along $\mathrm{CD}$

$\Delta D_{\mathrm{CD}}=c B_{0} g_{11}(\alpha, \beta) V_{1}$

where

$g_{11}=\frac{\cos \alpha \cos \phi}{\tan 2 \phi}\left(\mathrm{e}^{\beta \tan 2 \phi}-1\right)$

(d) Along the radial lines of the shear zone BCD

$\Delta D_{\mathrm{rad}}=\Delta D_{\mathrm{CD}}$ 
44. The total incremental energy dissipation is the summation of these four parts: that is, equations (47), (49), (51) and (53)

$$
\Sigma[\Delta D]=\Delta D_{\mathrm{AC}}+\Delta D_{\mathrm{DE}}+\Delta D_{\mathrm{CD}}+\Delta D_{\mathrm{rad}}
$$

\section{References}

1. TERZAGHI K. Theoretical soil mechanics. John Wiley and Sons, New York, 1943.

2. MeyerhoF G. G. The ultimate bearing capacity of foundations. Géotechnique, 1951, 2, 301-332.

3. SoKolovsKI V. V. Statics of granular media. Pergamon Press, New York, 1965.

4. PRAKASH S. and SARAN S. Bearing capacity of eccentrically loaded footings. J. Soil Mech. Foundn Engng Div. Am. Soc. Civ. Engrs, 1971, 97, No. 1, 95-117.

5. SARAN S. Bearing capacity of footings under inclined loads. Seminar on foundation problems. Indian Geotechnical Society, New Delhi, 1971, Vol. II, 4-5.

6. CHEN W. F. Limit analysis and soil plasticity. Elsevier Scientific, London, 1975.

7. SARAN S. and AGARWAL R. K. (1991). Bearing capacity of eccentrically obliquely loaded footing. J. Geotech. Engng Div. Am. Soc. Civ. Engrs, 117, No. 11, 1669-1690.

8. MeYerhoF G. G. (1953) The bearing capacity of foundations under eccentric and inclined loads. Proceedings of the 3rd international conference on soil mechanics and foundation engineering, Zurich, 1953, Vol. 1, 440-445.

9. Shinohara T., TATEIShI T. and Kubo K. Bearing capacity of sandy soil for eccentric and inclined load and lateral resistance of single piles embedded in sandy soil. Proceedings of the 2nd world conference on earthquake engineering, Tokyo, 1960, Vol. 1, 265-280.

10. SARMA S. K. and IOSSIFELIS I. S. Seismic bearing capacity factors of shallow strip footings. Géotechnique, 1990, 40, No. 2, 265-273.

11. Soubra A. H. and Reynolds F. (FACCiOlli E. and
Pecker A. (eds)) Design charts for the seismic bearing capacity of strip footings on slopes. Proceedings of the French-Italian conference on slope stability in seismic areas, Bordighera, 1992, 273-283, Ouest éditions.

12. DormieuX L. and Pecker A. Seismic bearing capacity of foundations on cohesionless soil. J. Geotech. Engng Div. Am. Soc. Civ. Engrs, 1995, 121, No. 3, March, 300-303.

13. Soubra A. H. (Owen D. R. J. (ed.)) Seismic bearing capacity of strip footings. Proceedings of the 3rd international conference on computational plasticity. Pineridge Press, Barcelona, 1992, 995-1006.

14. Soubra A. H. Discussion on 'Seismic bearing capacity and settlement of foundations' by Richards R., Elms D. G. and Budhu M. J. Geotech. Engng Div. Am. Soc. Civ. Engrs, 1994, 120, No. 9, 1634-1636.

15. RichARDS R., Elms D. G. and Budhu M. Seismic bearing capacity and settlement of foundations. J. Geotech. Engng Div. Am. Soc. Civ. Engrs, 1993, 119, No. 4, 662-674.

16. BudHu M. and AL-KarNi A. Seismic bearing capacity of soils Géotechnique, 1993, 43, No. 4, 181-187.

17. Muns H. and Kahl H. Ergebnisse V on Probebelastungen und grossen Lastflachen Zur Ermittlung der Bruch last in sand. Mitteilungen der DEGEBO, 1954, 8 (in German).

18. FEDA J. Research on bearing capacity of loose soil. Proceedings of the 5th international conference on soil mechanics and foundation engineering, Paris, 1961, Vol. I, 635-642.

19. Selig E. T. and McKeE K. E. (1961). Static and dynamic behavior of small footings. J. Soil Mech. Foundn Engng Div. Am. Soc. Civ. Engrs, 1961, 87, No. 6, 29-47.

20. DEBEER E. E. Bearing capacity and settlement of shallow foundations on sand. Proceedings of symposium on bearing capacity and settlement of foundations, Durham, North Carolina, 1965, 15-34. 